\title{
Studying the effect of hydroxyapatite particles in osteoconductivity of Ti-HA bioceramic
}

\author{
Davood Bovand $^{1} \cdot$ Mohammad Reza Allazadeh $^{2}$ (D) $\cdot$ Susan Rasouli ${ }^{3} \cdot$ Erfan Khodadad $^{4} \cdot$ Ehsan Borhani $^{5}$
}

Received: 28 June 2018 / Revised: 4 August 2018 / Accepted: 14 August 2018 / Published online: 4 September 2018

(C) The Author(s) 2018

\begin{abstract}
Ball milling method and powder metallurgy technology were employed to synthetize metal matrix composites (MMC) for bone grafts' applications. The raw powder of the MMC was prepared by mechanical alloying of pure titanium (Ti) powder with hydroxyapatite (HA) particles. The biocompatibilities of the sintered Ti-HA composites were examined after immersing the samples in simulated body solution (SBF) for different periods of time. SEM image and XRD results analysis were utilized to study the effect of HA on osteoconductivity of the Ti-HA composite. To this purpose, several composites were synthetized from different Ti-HA raw powder combination based on the HA particle size, milling time, and the mass fraction of HA content (\% w/w) in the MMC. In vitro analysis of Ti-HA composite shows that composite with $30 \%$ w/w HA has higher bioactivity in comparison with composite containing pure Ti with 10\% w/w HA.
\end{abstract}

Keywords Powder technology $\cdot$ Synthetic bone grafts $\cdot$ Metal matrix composites (MMC) $\cdot$ Hydroxyapatite (HA) $\cdot$ Simulated body solution · Bioceramic

\section{Introduction}

Titanium and its alloys are the most common metal in medical devices and implants due to their impressive corrosion resistance,

Mohammad Reza Allazadeh

mrallazadeh@yahoo.com

Davood Bovand

davood_bovand@yahoo.com

Susan Rasouli

rasouli@icrc.ac.ir

Erfan Khodadad

khodadaderfan@mail.dlut.edu.cn

Ehsan Borhani

e.borhani@semnan.ac.ir

1 Materials and Metallurgical Engineering Department, Semnan University, Semnan, Iran

2 University of Strathclyde, DMEM (AFRC), G11XJ Glasgow, UK

3 Department of Nano-materials \& Nano-coatings, Institute for Colour Science and Technology, Tehran 1668814811, Iran

4 Department of Material Science, Dalian University of Technology, Dalian, China

5 Department of Nanotechnology, Nano-materials Group, Semnan University, Semnan, Iran osteoconductivity, bio-adhesion (bone ingrowths), modulus of elasticity, etc. Nevertheless, pure titanium (Ti) shows lack of desirable bioactive properties, particularly, bone-growth. Recent researches showed that it is possible to improve titanium's orthopedic implant fixation and surface bioactivity by coating it with biomaterial ceramics, such as hydroxyapatite (HA) or other calcium phosphate $(\mathrm{CP})$ forms $[1,2]$. HA with $\mathrm{Ca}_{10}\left(\mathrm{PO}_{4}\right)_{6}(\mathrm{OH})_{2}$ chemical formula has been widely used as bioactive material for a bone substitute because of its chemical similarities with the mineral components of bones. However, the current coatings techniques are prone to wearing or delamination [3].

The metal matrix composites (MMCs) are comprising rigid ceramic reinforcements embedded in a ductile metal or alloy metal matrix [4, 5]. The properties of MMCs are widely recognized to be controlled by the size and volume fraction of the reinforcements as well as by the nature of the matrix/ reinforcement interfaces. During the last decades, considerable research efforts have been directed to deploy MMCs production methods to develop reinforced Ti matrix composite using HA particles to improve the bioactivity and mechanical properties of the composite for medical applications [6-8].

In the present study, several Ti-Ha composites were sintered by applying ball milling method and powder metallurgy technology to serve as synthetic bone grafts. A series of experiments were conducted to study the effect of HA particle 
characterizations, introduced by initial HA particle size, specified HA percentages in the raw powder mixture, and the mechanical alloying milling time on bioactivity of sintered Ti-Ha composite. The in vitro studies of Ti-HA composites were performed using simulated body fluid (SBF) solution and surface morphology. Phase constituent of the composites are determined through SEM and XRD results. SEM provides the phase constituent of the composites before immersion in SBF while XRD gives the phase constituent of the composites after immersion in SBF.

\section{Sample preparation}

HA powders with 150 -nm particle size were prepared by rapid microwave synthesis according to Bovand et al.'s methodology [9]. The micron-size HA with $15-\mu \mathrm{m}$ particle size was synthesized by co-precipitation method described in Sousa et al.'s research work [10].

Figure 1 shows SEM morphologies of the HA powders for the nano-size (Fig. 1a) and micron-size (Fig. 1b) HA powders with spherical- and rod-like morphology. The Ti powder $(<$ $45 \mu \mathrm{m})$ from Merck KGaA was mixed with 10 and $30 \%$ w/w HA powders with $150 \mathrm{~nm}$ as well as $15-\mu \mathrm{m}$ size to have four Ti-HA mixture types. Half of each Ti-HA mixture group was milled for $20 \mathrm{~h}$, and the other half was milled for $50 \mathrm{~h}$ to have eight Ti-HA powder combinations, labeled as $\mathrm{C} 1$ to $\mathrm{C} 8$ in Table 1.

Ti-HA powder combinations with 15- $\mu$ m HA particles are labeled as Ti-mHA, while Ti-HA powder combinations with 150-nm HA particles are labeled as Ti-nHA. The mechanical milling was occurred in a planetary ball mill equipped with hardened steel jar and stainless steel balls. The milling was performed under argon atmosphere to avoid unexpected reactions during ball milling. The ball mill parameters were $300 \mathrm{rpm}$ for rotation speed and 1:10 for the mass ratio of powder to the balls. Subsequently, the milled powders were pressed mechanically at a pressure of $600 \mathrm{MP}$ in uniaxial steel dies to produce pellets with diameter of $20 \mathrm{~mm}$ and $10 \mathrm{~mm}$. The pellets were sintered at $1150^{\circ} \mathrm{C}$ with approximate heating rate of $7{ }^{\circ} \mathrm{C} / \mathrm{min}$ for $2 \mathrm{~h}$ in a laboratory electric furnace under argon media. All sintered pellets were mechanically polished with $\mathrm{SiC}$ paper in water, and then, ultrasonically rinsed with distilled water.

\section{Experimental procedure}

The chemical compositions of the composite surface were analyzed by EDXA, and its morphology was examined by LEO-1455VP SEM. The SBF was prepared to have ionic concentration near to human blood plasma based on the procedure developed by kokubo to investigate biocompatibility of Ti-HA composites [11]. The SBF was prepared by sequentially dissolving of $\mathrm{NaCl}, \mathrm{NaHCO}_{3}, \mathrm{KCl}, \mathrm{K}_{2} \mathrm{HPO}_{4} \cdot 3 \mathrm{H}_{2} \mathrm{O}$, $\mathrm{MgCl}_{2} \cdot 6 \mathrm{H}_{2} \mathrm{O}, \mathrm{CaCl}_{2}, \mathrm{Na}_{2} \mathrm{SO}_{4}$ and tris buffer in 11 of deionized water. $\mathrm{pH}$ of solution was adjusted to 7.4 by addition of $1 \mathrm{M} \mathrm{HCl}$ solution at $36.5^{\circ} \mathrm{C}$. Table 2 gives the ion concentration of SBF solution and its comparison with human blood plasma.

The wettability of the composites was determined by measuring of contact angle through sessile drop method. The wettability measurement was performed using data physicsoca 15 plus equipment (Filderstadt, Germany) with CCD camera at room temperature in air with $0.5 \mu \mathrm{l}$ droplet volume. The composite surface was polished by $1000 \mathrm{SiC}$ paper in one direction and rinsed by ultrasonic in distilled water bath to remove any contamination. The contact angle was measured at three different points on the surface of composite and pure $\mathrm{Ti}$ sample.

Figure 2 exhibits the SEM micrograph of $\mathrm{C} 2$ and $\mathrm{C} 3$ samples. It is observable in Fig. 2 that $30 \%$ w/w HA content titanium composite has higher porosity in compare to $10 \%$ $w / w$ HA content composite. Therefore, higher percentage of HA content lowers the density of the composite. TEM bright field microstructure images of $\mathrm{C} 2$ sample in Fig. $2 \mathrm{c}$ is the evidence of crashing Ti and HA particles to form nanocomposite materials. The pellets of Ti-HA composite were soaked in SBF solution with $40 \mathrm{ml} / \mathrm{g}$ ratio of solution volume $(\mathrm{ml})$ to weight of powder sample (g) to investigation the microstructure. Therefore, three different series of pellets were immersed in plastic jars containing SBF with $0.1 \mathrm{~cm}^{2} / \mathrm{ml}$ ratio of surface
Fig. 1 SEM image of starting powders. a Nano-size HA. b Micron-size HA

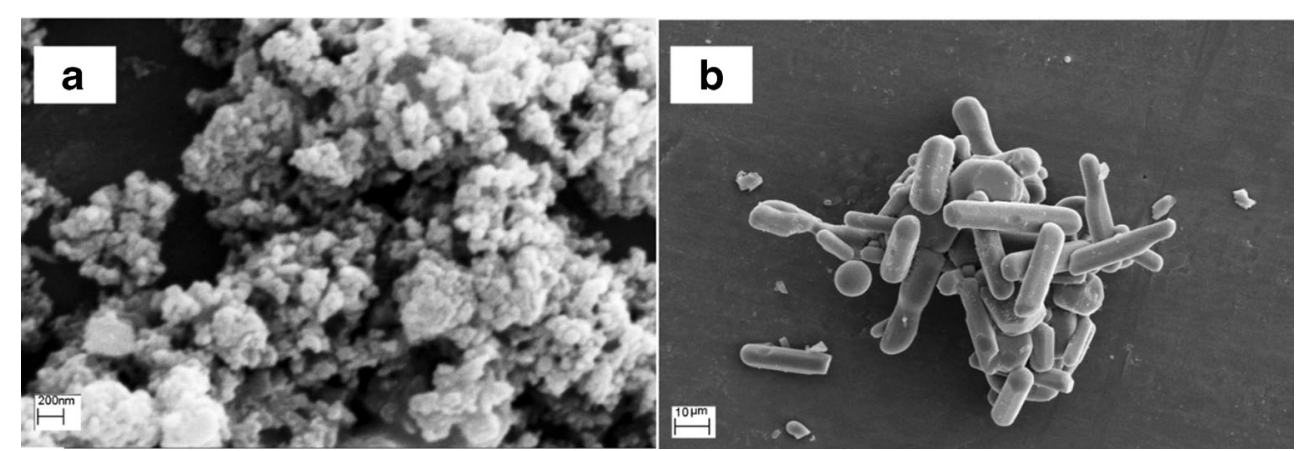


Table 1 Ti-HA mixture combinations' characterizations

\begin{tabular}{|c|c|c|c|c|c|c|c|c|c|}
\hline Ti-HA mixture ID & & $\mathrm{C} 1$ & $\mathrm{C} 2$ & $\mathrm{C} 3$ & $\mathrm{C} 4$ & $\mathrm{C} 5$ & C6 & $\mathrm{C} 7$ & $\mathrm{C} 8$ \\
\hline \multirow[t]{3}{*}{ Ti-HA mixture characterizations } & HA particle size & $15 \mu \mathrm{m}$ & $150 \mathrm{~nm}$ & $15 \mu \mathrm{m}$ & $150 \mathrm{~nm}$ & $15 \mu \mathrm{m}$ & $150 \mathrm{~nm}$ & $15 \mu \mathrm{m}$ & $150 \mathrm{~nm}$ \\
\hline & $w / w(\%)$ & 30 & 30 & 10 & 10 & 30 & 30 & 10 & 10 \\
\hline & Milled time (h) & 50 & 50 & 20 & 20 & 20 & 20 & 50 & 50 \\
\hline
\end{tabular}

area $\left(\mathrm{cm}^{2}\right)$ to solution volume $(\mathrm{ml})$. Then, the jars were put into an air oven thermostat at $36.5^{\circ} \mathrm{C}$ to soak the sintered TiHA powder samples. The sample were removed every 7 days to investigate the effect of soaking time on formation of apatite layer. The solution's $\mathrm{pH}$ was measured in order to investigate phase constituent and $\mathrm{pH}$ of SBF solution. Likewise, the powder sample of Ti-HA composite were soaked in SBF solution for 2 months for phase analysis with X-ray diffraction. The SBF solution refreshed every $24 \mathrm{~h}$ to accelerate the apatite layer formation, and also, to make easier identification of the apatite layer. The samples were retrieved after 7, 14, 21, 28, and 56 days in contact with SBF for characterization of constituent phase formed during immersion in SBF.

\section{Results and discussion}

Figure 3 shows the effect of immersion time on the $\mathrm{pH}$ value of SBF solution. The $\mathrm{pH}$ of solution was 7.4 before immersion which is similar to human body. At the early stage of the process, it can be seen that the $\mathrm{pH}$ value increases slightly as the immersion time increases. Initially, $\mathrm{OH}^{-}$accumulation on the surface of the composite is responsible for increasing the $\mathrm{pH}$ value of the composite. At the later stage, the $\mathrm{pH}$ value reaches to its maximum value of $7.86,7.71$, and 7.60 for the samples containing 30\% $\mathrm{HA}(w / w), 10 \% \mathrm{HA}(w / w)$, and $0 \%$ $\mathrm{HA}(w / w)$, respectively. Longer immersion time causes the $\mathrm{pH}$ of the composition decreasing gradually. After 16 days' immersion time, the $\mathrm{pH}$ for pure Ti sample approaches the $\mathrm{pH}$ of human blood plasma, i.e., approximately 7.4. The $\mathrm{pH}$ of the sample continues to decrease slightly but the reduction is so small that may not harm the body. The $\mathrm{pH}$ value of Ti-HA $30 \%(w / w)$ composite was found to be higher than Ti-HA $10 \%$ $(w / w)$ and pure Ti samples. Dissolving of $\mathrm{Ca}^{2+}$ ion by SBF solution results in increasing of $\mathrm{pH}$ in early stage of the immersion. Exchange of $\mathrm{Ca}^{2+}$ and $\mathrm{H}^{+}$pileups the $\mathrm{OH}^{-}$on the surface of composite, which is in favor of apatite nucleation. Accumulation of $\mathrm{OH}^{-}$and $\mathrm{PO}_{4}{ }^{3-}$ ions attract $\mathrm{H}^{+}$and $\mathrm{Ca}^{2+}$, and induce negative charge on composites' surfaces. This process proceeds through spontaneous reactions contain precipitation, nucleation, and growth of apatite layers on the surface of the composite [12-15].

Figure 4 demonstrates the representative XRD of Ti-HA composite before and after immersion in the SBF for various periods of time. The apatite phase concentration was not noticeable in XRD results even after 2 weeks since it was lower than the X-ray instrument detectability. Some weak peaks in graph B of Fig. 4 can be noticed for the apatite phase of pure Ti after immersion in SBF for 4 weeks, as compare to XRD result for pure Ti sample. The apatite peak related to Ti-HA composite becomes more intense after 16 weeks, whereas, some weak peaks related to apatite were observed for the pure Ti sample. The rate of increase in intensity of peak related to apatite phase in composite was more in 30\% (w/w) HA composite compare to $10 \%(w / w)$ HA composite, regardless of milling time and initial HA particles size. This is the result of the greater apatite formation of the sample with higher HA content due to the higher concentration of $\mathrm{Ca}^{2+}$ and $\mathrm{TiO}_{2}$ in comparison to the pure Ti sample or the $10 \% w / w$ HA content composite.

Figure 5 shows the microstructure of Ti-HA composite before immersion in SBF. Figure 5 also gives evidence of non-homogenous distribution of $\alpha-\mathrm{Ti}+\mathrm{Ca}_{3}\left(\mathrm{PO}_{4}\right)_{2}$, known as TCP, $\mathrm{CaTiO}_{3}$, and $\mathrm{Ti}_{5} \mathrm{P}_{3}$ in the Ti-HA composite, which was discussed in the authors' previous article [16].

The reaction product of HA and $\mathrm{Ti}$ (consist of $\mathrm{Ca}_{3}(\mathrm{PO} 4)_{2}$, $\mathrm{CaTiO}_{3}$, and $\mathrm{Ti}_{5} \mathrm{P}_{3}$ ) formed during sintering process in Ti$30 \% w / w$ HA is accumulated in the outer layer of titanium particle (Fig. 5a). This can be attributed to higher degree of non-homogeneity in higher HA content composite. Images of the EDXA spectra of the composite in Fig. 7 reveals that high concentration of $\mathrm{Ca}$, $\mathrm{P}$, and $\mathrm{O}$ exists in pores and the intergranular spaces, while Ti is the dominant element in the middle of the grain.

Figure 6 shows SEM image of pure Ti sample and Ti-HA composite which immersed in SBF solution for different time
Table 2 Ion concentrations of $\mathrm{SBF}$ and human blood plasma $(\mathrm{mmol} / \mathrm{l})$

\begin{tabular}{lcccccccc}
\hline Sample & $\mathrm{Na}^{+}$ & $\mathrm{K}^{+}$ & $\mathrm{Ca}^{2+}$ & $\mathrm{Mg}^{2+}$ & $\mathrm{HCO}_{3}^{-}$ & $\mathrm{Cl}^{-}$ & $\begin{array}{l}\mathrm{HPO}_{4}{ }^{2} \\
\mathrm{SO}_{4}{ }^{2+}\end{array}$ \\
\hline Blood plasma & 142.0 & 5.0 & 2.5 & 1.5 & 27.0 & 103.0 & 1.0 & 0.5 \\
SBF & 142.0 & 5.0 & 2.5 & 1.5 & 4.2 & 147.8 & 1.0 & 0.5 \\
\hline
\end{tabular}


Fig. 2 Scanning electron micrograph of $\mathbf{a} \mathrm{C} 2$ and $\mathbf{b} \mathrm{C} 3$. $\mathbf{c}$ TEM micrograph of $\mathrm{C} 2$

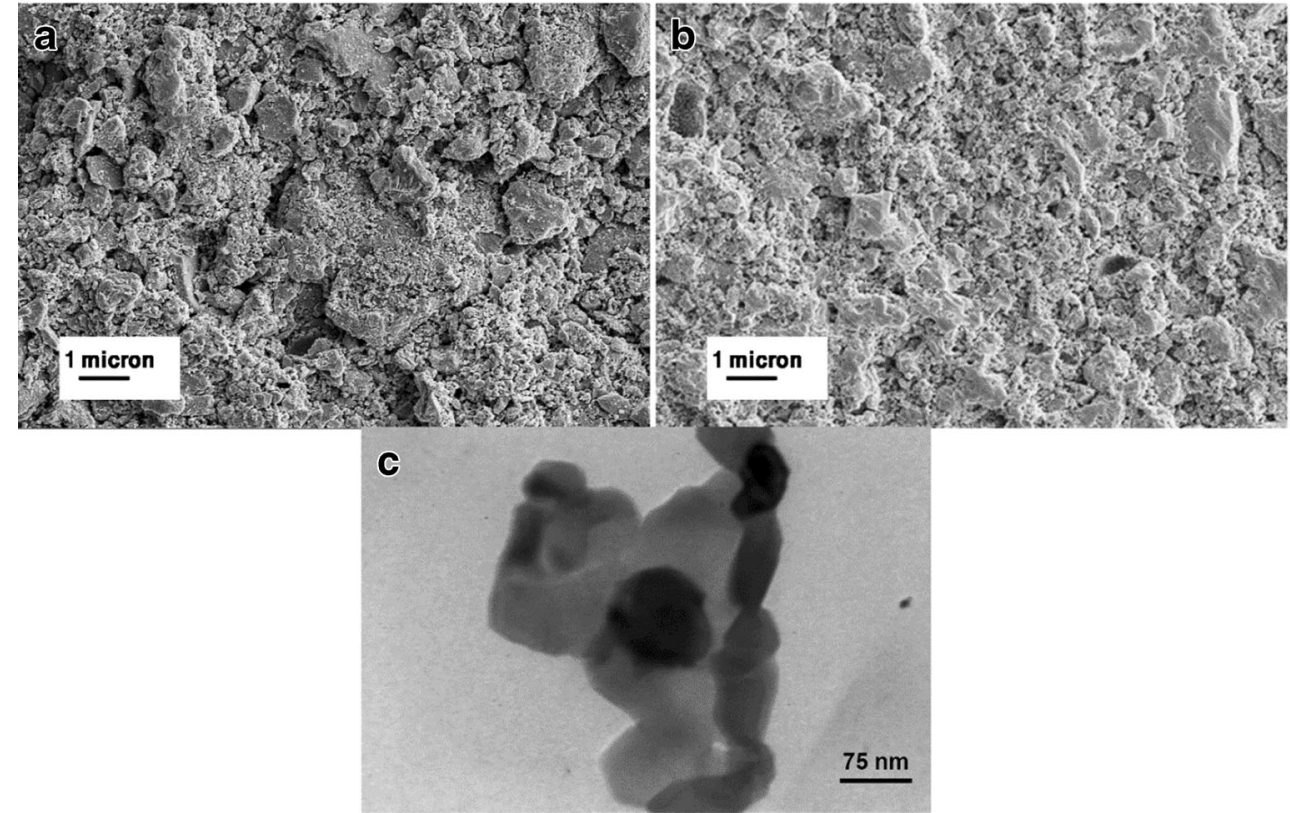

span. From Fig. 6, it can be noticed that after 2 weeks the sphere-like apatite distributed irregularly with different sphere size and precipitate on the surface of composite. Figure $6 \mathrm{~d}, \mathrm{f}$ suggests that more apatite was precipitated for longer immersion time, such that after 4 weeks the surface of composite completely covered with layer of apatite (Fig. 6c and e). While no considerable apatite layer was found for pure Ti sample even after 2-week immersion, some sphere-like apatite were observed after 4 weeks' immersion. Unlike Ti sample, the apatite layer of Ti-HA composite can be distinguished easily after 2 weeks (Fig. 6d and f). However, precipitated layer of apatite in Ti-HA $30 \mathrm{wt} \%$ was more than Ti-HA $10 \mathrm{wt} \%$, regardless to the initial HA size and milling time.

The samples were examined for the pollution with related to the milling jar and balls. No contamination was found in the XRD results of the samples; however, EDXA analysis shows small trace of $\mathrm{Cr}$ and $\mathrm{Fe}$ in some regions of the sample with $50 \mathrm{~h}$ milling.

Figure 7 compares the mapping of elements on the surface of pure $\mathrm{Ti}, \mathrm{C} 2$, and $\mathrm{C} 8$ samples. In case of pure $\mathrm{Ti}$, small amount of $\mathrm{Ca}$ was detected after 2 weeks which cannot be visible in SEM image because of low concentration. Nevertheless, more Ca were detected by EDXA in case of $\mathrm{C} 2$ and $\mathrm{C} 8$ samples. In Fig. $7 \mathrm{~b}$ and c, irregular distribution of $\mathrm{Ca}$ can be found for Ti-HA composite, and hence, some regions within the microstructure can be distinguished as calcium-poor and calcium-rich areas. The selective precipitation of apatite seems to be as result of forming different phases in Ti-HA composite during sintering process [16].

The Ti rich region has lower bioactivity, and therefore, selective precipitation of apatite layer was done in areas with higher HA phases. Since higher concentration of ceramic phases are on the pores and inter-granular areas, the apatite layers tend to precipitated in these locations rather than on the middle of the grain with higher Ti phases. Table 3 lists the measured contact angle for different Ti-HA composite. Ti-HA composite with $30 \% \mathrm{w} / \mathrm{w}$ HA shows higher wettability than Ti-HA $10 \% w / w$ and pure Ti sample. Thereof, it is reasonable to conclude that the wettability of the composite will improve with increase in HA content.
Fig. 3 Measured $\mathrm{pH}$ of SBF solution related to different Ti-HA composite and pure $\mathrm{Ti}$
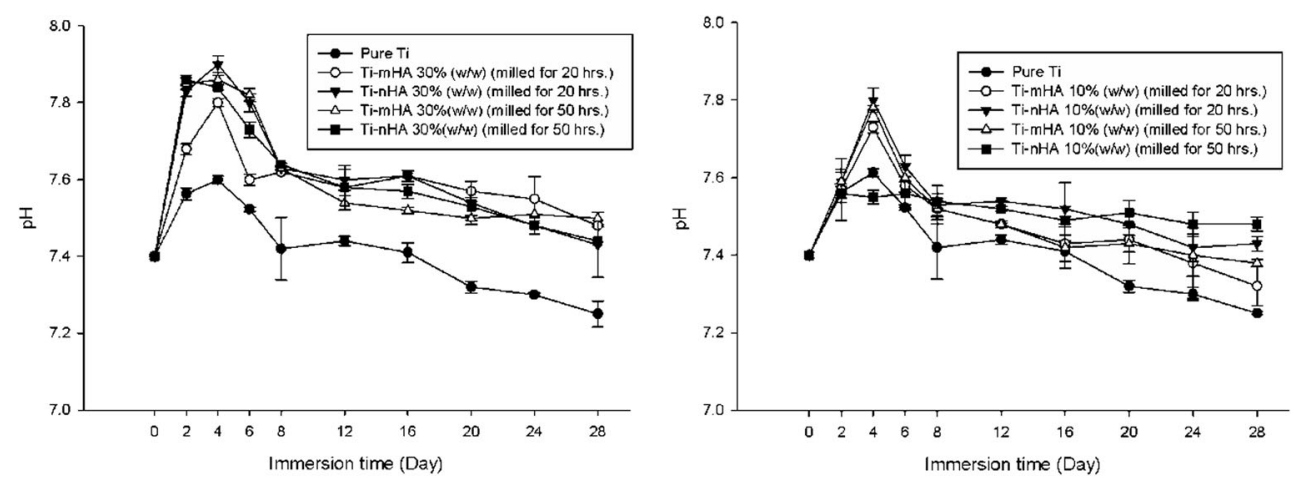

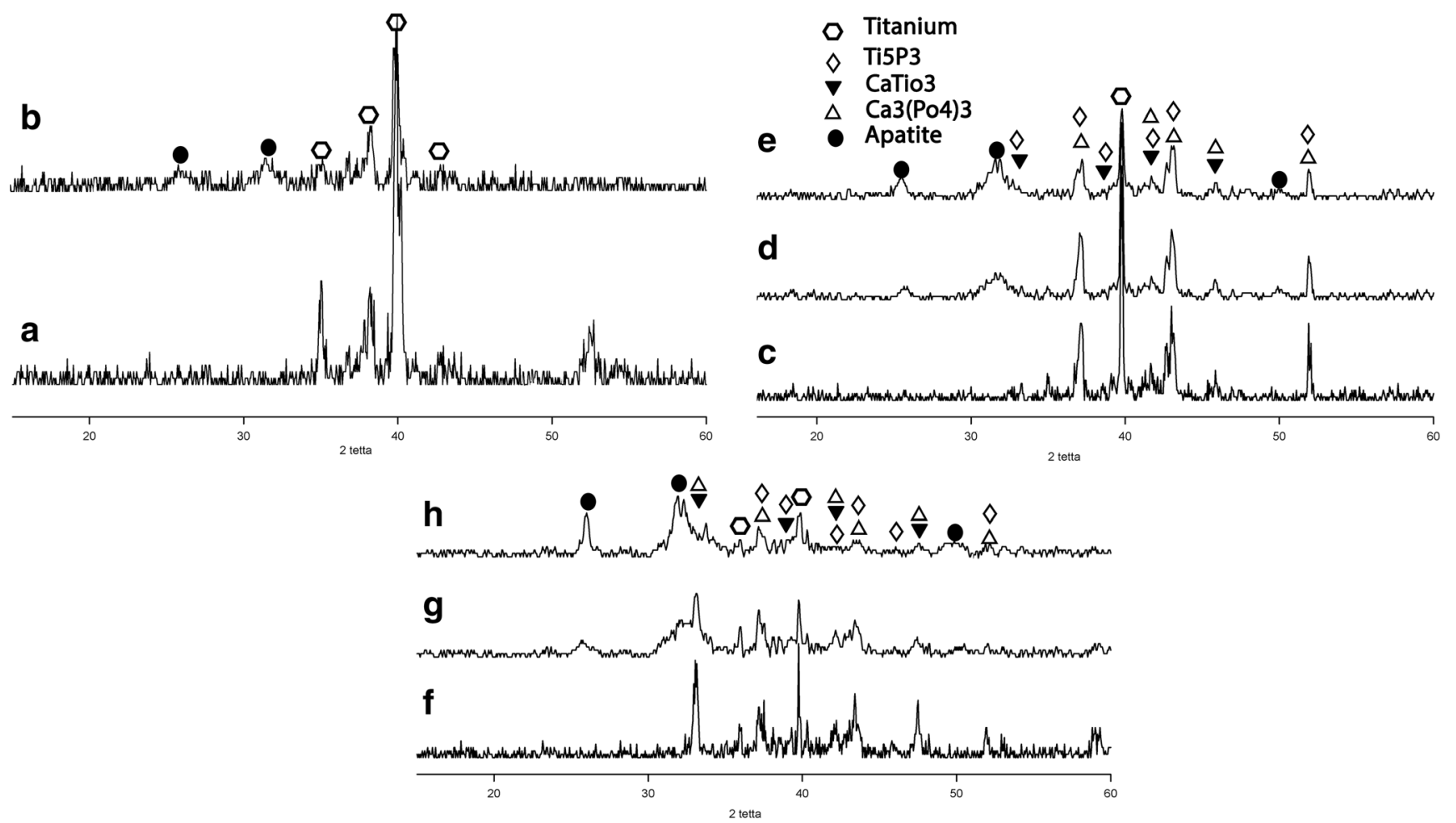

Fig. 4 XRD spectra of sintered HA-Ti samples. a Pure Ti sample. b Pure Ti sample after 4 weeks immersion in SBF. c Sample C2. d C2 after 4 weeks immersion. e C2 after 8 weeks immersion. f Sample C7. g C7 after 4 weeks immersion. h C7 after 8 weeks immersion

Fig. 5 SEM image of a C8: TinHA $10 \%(w / w)$ (milled for 50 h.), b C4 Ti-nHA 10\% (w/w) (milled for $20 \mathrm{~h}$.), and c C6: TinHA 30\% (w/w) (milled for $20 \mathrm{~h}$ )

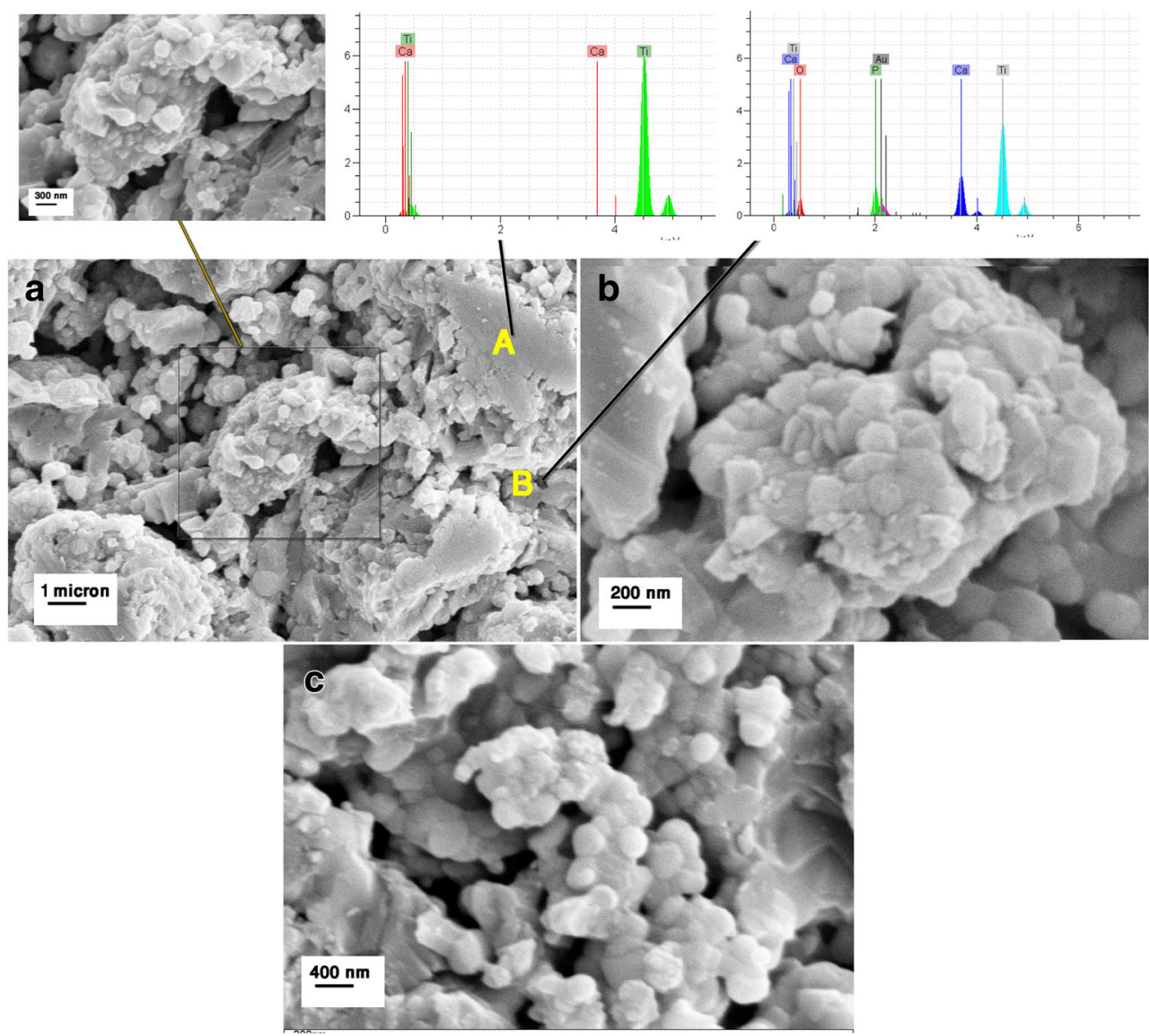


Fig. 6 SEM image of a pure Ti sample after 1 week immersion, $\mathbf{b}$ pure Ti sample after 2 week immersion, C C3: Ti-mHA 10\% $(w / w)$ (milled for $20 \mathrm{~h}$.) after 4 week immersion, $\mathbf{d}$ C3 after 2 week immersion, e $\mathrm{C} 2$ : Ti-nHA $30 \%(w / w)$ (milled for $50 \mathrm{~h}$ ) after 4 immersion, and $\mathbf{f} \mathrm{C} 2$ after

2 week immersion
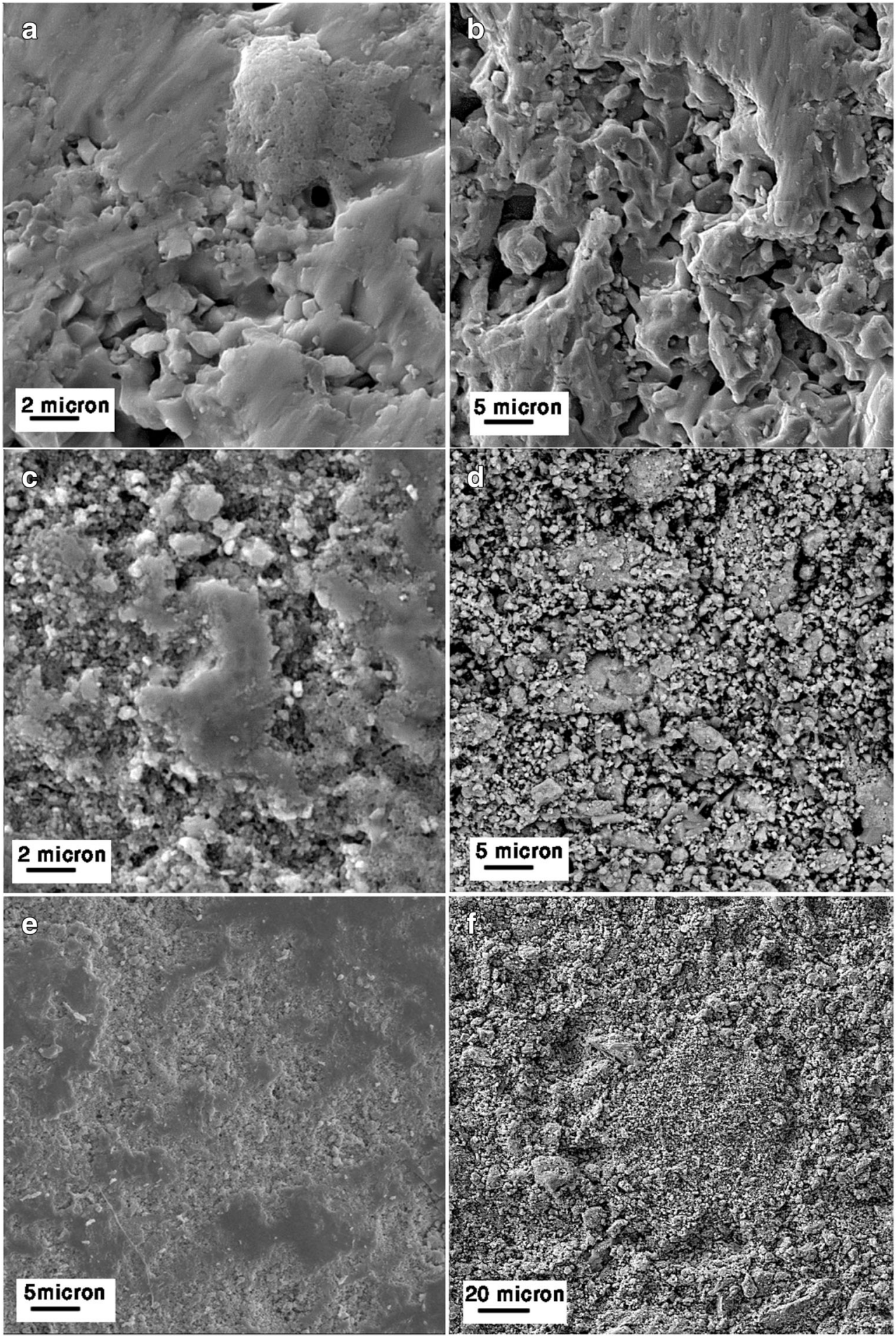

The chemical and topographical properties of the surface are important factor for biomedical materials (Fig. 8). Higher wettability improves the implant performance in the body [17].

The contribution of milling time and initial HA powder size is through determining the final surface roughness of the ceramic in the composite whose influence enhances the Ti-HA composite wettability. The wettability can be measured by contact angle of substrate with the given liquid according to the balance at solid, liquid, and vapor phases given by young equation:

$\gamma_{s v}=\gamma_{s l}+\gamma_{l v} \cos \theta_{\gamma}$ 

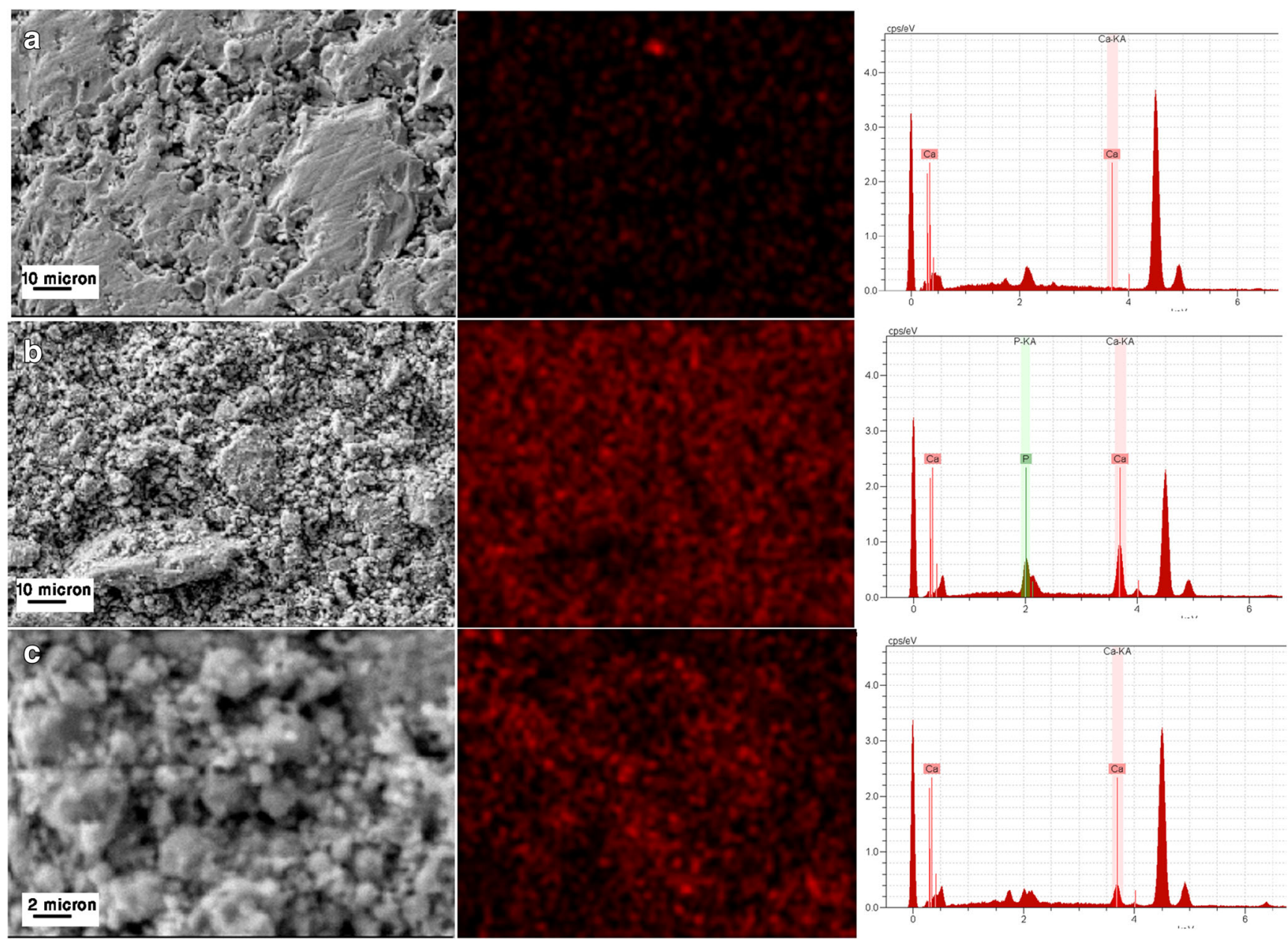

Fig. 7 SEM image. Mapping of Ca and EDXA related to a pure Ti sample, b C2: Ti-nHA 30\% (w/w) (milled for $50 \mathrm{~h}$.), and c C8: Ti-nHA 10\% ( $w / w)$ (milled for $50 \mathrm{~h}$ )

where $\gamma_{s v} \gamma_{s l}, \gamma_{l v}$ and $\theta_{\gamma}$ are interfacial tension of solidvapor, solid-liquid, liquid-vapor, and the contact angle, respectively.

It is worth to note that surface roughness will enhance the wettability caused by the chemistry of the surface

Table 3 Measured contact angle of Ti-HA composite and pure $\mathrm{Ti}$ samples

\begin{tabular}{lll}
\hline Sample & $\begin{array}{l}\text { Mean value of } \\
\text { contact angle }\end{array}$ & $\begin{array}{l}\text { Standard } \\
\text { deviation }\end{array}$ \\
\hline c1 & 23.93 & 1.74 \\
c2 & 24.56 & 2.44 \\
c3 & 33.73 & 2.90 \\
c4 & 30.64 & 2.96 \\
c5 & 26.75 & 1.54 \\
c6 & 23.12 & 2.90 \\
c7 & 45.01 & 3.43 \\
c8 & 39.23 & 3.51 \\
$\mathrm{Ti}$ & 61.56 & 1.91 \\
\hline
\end{tabular}

defined by Wenzel [18], and it can be computed according to the equation in below:

$\operatorname{Cos} \theta_{m}=r \operatorname{Cos} \theta_{\gamma}$

where $\theta_{m}$ is measured contact angle, $\theta_{\gamma}$ is the contact angle on ideal surface (young contact angle), and $r$ is the surface roughness ratio which can be calculated from a 3D roughness parameter and varied from below one for rough surface to one for smooth surface.

Ceramics are hydrophilic, and consequently, enhance the surface wettability [17]. Increasing HA content improves wetting properties due to the higher surface roughness induced by the structure of HA, and also, by higher amount of ceramic phase in Ti matrix. In conclusion, two factors will increase the wettability of Ti-HA composite: (a) ceramic phases which formed during sintering and (b) increase of the surface roughness induce by HA. The wettability was better in case of Ti-HA composite with $30 \%$ $w / w$ HA than the other samples, regardless to its initial HA powder size and milling time. This is because of higher roughness of sample and higher amount of ceramic phases. 
Fig. 8 Images of sessile droplets of $\mathbf{a} \mathrm{C} 6, \mathbf{b} \mathrm{C} 8, \mathbf{c} \mathrm{C} 4$, and $\mathbf{d}$ pure $\mathrm{Ti}$ sample

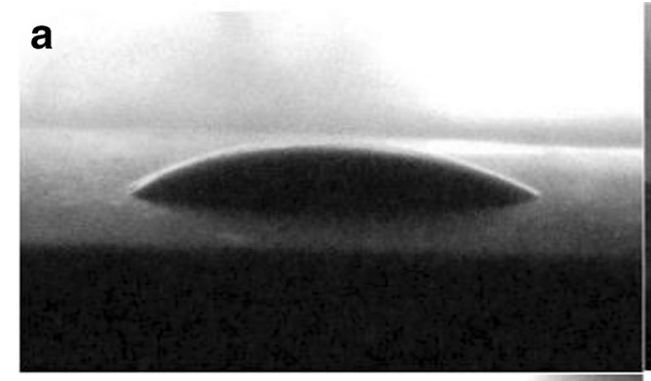

b

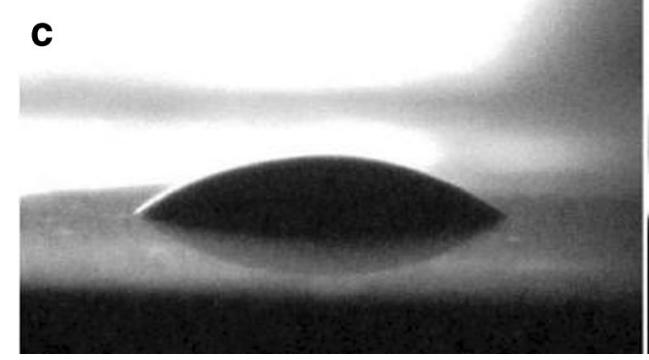

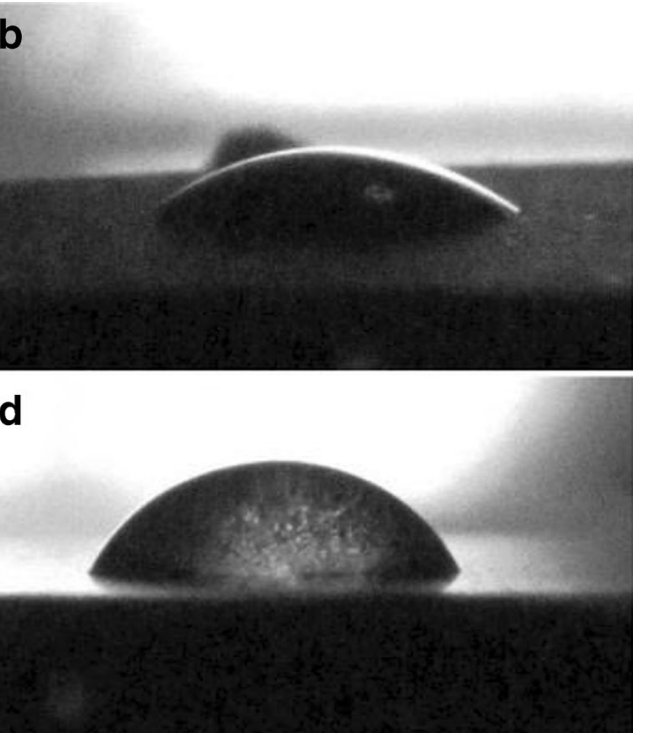

\section{Conclusion}

A synthetic bone grafts was introduced based on titanium matrix composite reinforced with hydroxyapatite (HA) particle prepared by mechanical alloying and powder metallurgy method.

The in vivo bioactivity of composites was scrutinized by immersing the samples in simulated body solution (SBF). Results show that increasing HA may improve bioactivity of composite since the sample with $30 \%$ w/w HA content shows better bioactivity compatibility in compare to the $10 \% w / w$ HA and $0 \% w / w$ HA content samples.

The sample with $30 \%$ w/w HA shows better wetting properties than other samples, and therefore, it can be concluded that increasing HA content could improve wettability of composite. The contribution of milling time and initial HA powder size on in vivo bioactivity of Ti-HA composite are through determining the final surface roughness of the ceramic in the composite whose influence enhance the Ti-HA composite wettability. Results showed that the $\mathrm{pH}$ for pure Ti sample approach the $\mathrm{pH}$ of human blood plasma, which indicates possible osteoconductivity of the suggested synthetized Ti-HA composite.

Further studies on the effect of various bioceramic associated with different sintering techniques, such as spark plasma sintering (SPS), may offer better optimization for MMC applicable for synthetic bone prosthesis.

\section{Compliance with ethical standards}

Conflict of interest The authors declare that they have no conflict of interest.

Open Access This article is distributed under the terms of the Creative Commons Attribution 4.0 International License (http:// creativecommons.org/licenses/by/4.0/), which permits unrestricted use, distribution, and reproduction in any medium, provided you give appropriate credit to the original author(s) and the source, provide a link to the Creative Commons license, and indicate if changes were made.

\section{References}

1. Yamada, K., Imamura, K., Itoh, H., Iwata, H., Maruno, S.: Bone bonding behaviour of the hydroxyapatite containing glass-titanium composite prepared by the cullet method. Biomaterials. 22, 2207 $2214(2001)$

2. Zhen-jun, W., Li-ping, H., Zong-zhang, C.: Fabrication and characterization of hydroxyapatite/ $\mathrm{Al} 2 \mathrm{O} 3$ biocomposite coating on titanium. Trans. Nonferrous Metals Soc. China. 16, 259-266 (2006)

3. Chang, J.-K., Chen, C.-H., Huang, K.-Y., Wang, G.-J.: Eight-year results of hydroxyapatite-coated hip arthroplasty. J Arthroplast. 21, (2006)

4. Berns, H.: Comparison of wear resistant $\mathrm{MMC}$ and white cast iron. Wear. 254, 47-54 (2003)

5. Ozban, T., Kilickap, E., Cakir, O.: Investigation of mechanical and machinability properties of SiC particle reinforced Al-MMC. J Mater Process Technol. 198, 220-225 (2008)

6. Ning, C., Zhou, Y.: Correlations between the in vitro and in vivo bioactivity of the Ti-HA composites fabricated by a powder metallurgy method. ActaBiomaterialia. 4(6), 1944-1952 (2008)

7. Salman, S., et al.: Sintering effect on mechanical properties of composites of naturalhydroxyapatites and titanium. Ceram Int. $\mathbf{3 5}$, 2965-2971 (2009)

8. Niespodziana, K., Jurczyk, K., Jakubowicz, J., Jurczyk, M.: Fabrication and properties of titanium-hydroxyapatite nanocomposites. Mater Chem Phys. 123(1), 160-165 (2010)

9. Bovand, N., Rasooli, S., Mohammadi, M.R., Bovand, D.: Rapid synthesis of hydroxyapatite nanopowders by a microwave-assisted combustion method. J Ceram Process Res. 13(3), 221-225 (2012)

10. Sousa, A., Souza, K., Souza, E.: Mesoporous silica/apatite nanocomposite: special synthesis route to control local drug delivery. Acta Biomater. 4(3), 671-679 (2008)

11. Ohtsuki, C., Kokubo, T., Yamamuro, T.: Mechanism of apatite formation on Cao-Sio2-P2O5 glasses in a simulated body-fluid. NonCryst Solids. 143, 84-92 (1992) 
12. Noam Eliaz, Noah Metoki, Calcium phosphate bioceramics: a review of their history, structure, properties, coating technologies and biomedical applications, Materials (Basel), PMCID: PMC5506916, V10(4): 334, (2017)

13. De Castro Juraski, A., et al.: The in vitro bioactivity, degradation, and cytotoxicity of polymer-derived wollastonite-diopside glass-ceramics. Materials. 10(4), 425 (2017). https://doi.org/10.3390/ ma10040425

14. Cziko, M., et al.: In vitro biological activity comparison of some hydroxyapatite-based composite materials using simulated body fluid. Cent Eur J Chem. 11(10), 1583-1598 (2013)
15. Kaygili, O., et al.: The effect of simulating body fluid on the structural properties of hydroxyapatite synthesized in the presence of citric acid. Prog. Biomater. 5, 173-182 (2016)

16. Bovand, D., et al.: Characterization of Ti-HA composite fabricated by mechanical alloying. Mater Des. 65, 447-453 (2015)

17. J. J. Callaghan, A. G. Rosenberg, and H. E. Rubash, The adult hip, J. J. Callaghan, A. G. Rosenberg, and H. E. Rubash, Eds. Lippincott-Raven Publishers, (1998)

18. Wenzel, R.N.: Resistance of solid surfaces to wetting by water. Ind Eng Chem. 28(8), 988-994 (1936) 